\title{
Effect of geographical latitude and sun exposure on Rufous Hornero (Furnarius rufus) nest orientation
}

\author{
Alejandro A. Schaaf ${ }^{1}$. Cecilia G. García ${ }^{1}$ - Patricia B. Puechagut ${ }^{2} \cdot$ Luna E. Silvetti $^{3}$ - Ever Tallei ${ }^{1}$. Fátima Ortis $^{4}$. \\ Agustín I. E. Quaglia 5
}

Received: 18 September 2017 / Revised: 6 May 2018 / Accepted: 7 June 2018

(c) Dt. Ornithologen-Gesellschaft e.V. 2018

\begin{abstract}
Bird nest orientation is affected by environmental variables determined by their geographical position as well as microclimatic conditions. In closed-cup-nesting species, nests may be oriented to avoid adverse environmental extremes such as sun exposure, wind, and rainfall, although vegetal cover may provide extra protection generating random orientation patterns. Here, we assess nest entrance orientation in Rufous Hornero (Furnarius rufus) at 11 South American sites by comparing nests well covered by vegetation ( $>75 \%$ covered) from those with less or non-external vegetal protection $(<25 \%)$. We estimated and compared mean entrance orientation between northern and southern locations and levels of vegetation cover using circular statistics $(n=1291)$. Additionally, the influence of geographical latitude and vegetation cover on nest orientation was evaluated using linear mixed models across sites with non-random nest-orientation patterns. Results showed differences in mean orientation values between covered and uncovered nests at most locations and directed entrance orientation for uncovered nests. On the other hand, the models indicate that nest entrance orientation is not affected by the joint effect of latitude and vegetation cover and high variability between locations. Local microclimatic conditions provided by the vegetation above nests are important determinants for nest orientation in the species, although additional information about local rainfall, wind, temperature, and nesting site availability may help to determine the factors affecting orientation in the species on a local level.
\end{abstract}

Keywords Nest orientation $\cdot$ Nest preference $\cdot$ South America $\cdot$ Ovenbird $\cdot$ Furnariidae

\section{Zusammenfassung}

Der Einfluss der geographischen Breite und der Sonneneinstrahlung auf die Nestausrichtung bei Rosttöpfern (Furnarius rufus) Die Ausrichtung von Vogelnestern wird von Umweltvariablen beeinflusst, die durch die geographische Position der Nester sowie die dortigen mikroklimatischen Bedingungen bestimmt werden. Bei Arten, die in geschlossenen Napfnestern brüten, können die Nester so ausgerichtet sein, dass sie widrige Umweltextreme, z. B. bezüglich Sonneneinstrahlung, Wind und Regen, vermeiden, wobei die Vegetation zusätzlichen Schutz bieten und zu einer zufälligen Ausrichtung des Nesteingangs führen kann. Hier untersuchen wir die Ausrichtung des Nesteingangs bei Rosttöpfern (Furnarius rufus) an 11 südamerikanischen Standorten und vergleichen stark durch Vegetation geschützte Nester $(>75 \%$ bedeckt) mit solchen, denen die Vegetation nur wenig oder gar keinen Schutz bietet ( $<25 \%$ bedeckt). Wir haben die mittlere Ausrichtung des Nesteingangs abgeschätzt und mit Hilfe von Kreisstatistik zwischen nördlichen und südlichen Standorten sowie Standorten mit unterschiedlicher Vegetationsbedeckung verglichen $(n=1291)$. Zusätzlich haben wir den Einfluss der geographischen Breite und der Vegetationsbedeckung auf die Nestausrichtung an Standorten, an denen die Nester nicht zufällig ausgerichtet waren, mit Hilfe linearer gemischter Modelle ausgewertet. Die Ergebnisse zeigten an den meisten Standorten Unterschiede in der mittleren Ausrichtung zwischen durch Vegetation geschützten und exponierten Nestern sowie eine gezielte Ausrichtung des Eingangs für exponierte Nester. Andererseits zeigen die Modelle, dass die Ausrichtung

Communicated by T. Gottschalk.

Alejandro A. Schaaf and Cecilia G. García have contributed equally to this work.

Extended author information available on the last page of the article 
des Nesteingangs nicht durch den gemeinsamen Effekt von geographischer Breite und Vegetationsbedeckung beeinflusst wird und die Variabilität zwischen Standorten hoch ist. Die lokalen mikroklimatischen Bedingungen, die durch die über dem Nest befindliche Vegetation zustande kommen, sind wichtige Faktoren für Nestausrichtung bei dieser Vogelart, wobei zusätzliche Informationen über örtliche Regenfälle, Wind, Temperatur und Nistplatzverfügbarkeit dabei helfen dürften, die Faktoren zu ermitteln, welche die Nestausrichtung auf lokaler Ebene beeinflussen.

\section{Introduction}

Avian nest site selection determines nest microclimate, exposing eggs and nestlings to different conditions of humidity, temperature, wind, and solar radiation during incubation and rearing (Collias and Collias 1984; Hartman and Oring 2003; Lloyd and Martin 2004). Since embryos and nestlings are highly sensitive to moisture and thermal conditions (Webb 1987), adults are likely to achieve higher nesting success by optimizing nest conditions (Webb and King 1983; Mainwaring et al. 2014). This may be accomplished either through behavioral adjustment by parents during incubation or through changes in nest location/orientation and design (Conway and Martin 2000; Hartman and Oring 2003; Mainwaring et al. 2016), with the latter being energetically cheaper than the former (Mainwaring and Hartley 2013).

Studies examining entrance orientation preferences show great variation among species, some of which have shown strong tendencies towards particular directions (Inouye et al. 1981; Norment 1993; Zwartjes and Nordell 1998; Hooge et al. 1999; Mezquida 2004; Lloyd and Martin 2004; Landler et al. 2014). Other studies, however, have revealed little or no preference in nest orientation at all (Albano 1992; Tarvin and Smith 1995; Souza and Santos 2007). Nest orientation has generally proved to be correlated with mean wind direction (Facemire et al. 1990; Mezquida 2004) and sun exposure (With and Webb 1993; Hartman and Oring 2003; Burton 2006). Birds can modify nest sun exposure depending on the geographical position (Petersen and Best 1985; Burton 2007; Landler et al. 2014; Mainwaring et al. 2016) and solar radiation received during daylight hours (With and Webb 1993; Hooge et al. 1999; Nelson and Martin 1999).

Temperature is the most important determinant of nest microclimate because it can dramatically influence embryonic viability (Webb 1987; Cook et al. 2003; Burton 2006; DuRant et al. 2013) and the energy balance of both the incubating adults and the developing nestlings (Webb and King 1983; Visser and Lessells 2001; Hanssen et al. 2005). Thus, nest orientation can help in the optimization of nest temperature by the adults (Brown and Downs 2003; Hartman and Oring 2003). Moreover, vegetation cover may have an effect on nest orientation generating random and non-random values since its presence may offer protection against wind, solar radiation, or predation (Martin and Roper
1988; Norment 1993; Hoekman et al. 2002; Souza and Santos 2007). On the other hand, wind can ease nest refrigeration through convection (Facemire et al. 1990; Viñuela and Sunyer 1992; Norment 1993).

In closed-cup, open-cup and cavity-nesting species, nests may be oriented to avoid adverse environmental extremes such as sun exposure, wind, and rainfall (Hartman and Oring 2003; Burton 2007; Landler et al. 2014). In addition, nest orientation may vary even within a bird species, in relation to latitude, altitude, topography or when considering a single reproductive season due to changing climate conditions (Rauter et al. 2002; Burton 2007; Landler et al. 2014).

Rufous Hornero is a species of the Furnariidae family, widely known as ovenbirds. This species constructs nests which consist of a dome structure made of clay, mixed with plant fibers, hair, or dung (Zyskowski and Prum 1999). The nests are frequently seen in trees and on lampposts (Fig. 1) in rural and urban areas (Ridgely and Tudor 1994). The species is widely distributed in South America including Bolivia, Brazil, Argentina, Uruguay, and Paraguay (Fraga 1980) (Fig. 1), and its nesting period extends from September to March. After this period nests can be repaired and reused in a new breeding season or abandoned. Thus, it is common to see several nests close to each other (or even on top of older nests) at the same nesting site (Peña 2005).

According to anecdotal information for Argentinean populations of Rufous Hornero, nest openings have a southsouthwestern orientation in response to the local wind direction (Fraga 1980). On the other hand, previous data for the species in Brazil reported a random pattern of nest entrance orientation, regardless of local climate conditions and the absence of vegetation cover (Souza and Santos 2007).

In this study, we analyze nest entrance orientation in Rufous Hornero in a wider range of its distribution at 11 sites belonging to different ecoregions across four South American countries, considering vegetation cover as a microhabitat condition. Based on Souza and Santos (2007), if nest entrance varies in relation to solar radiation we expect a nonrandom orientation toward southern directions in uncovered nests at lower latitudes to be protected against strong solar radiation from northern directions, and a random orientation pattern for covered nests. Considering the hypothesis that yearly mean temperatures influence entrance orientation in birds (Wiebe 2001; Burton 2007; Landler et al. 2014), we 


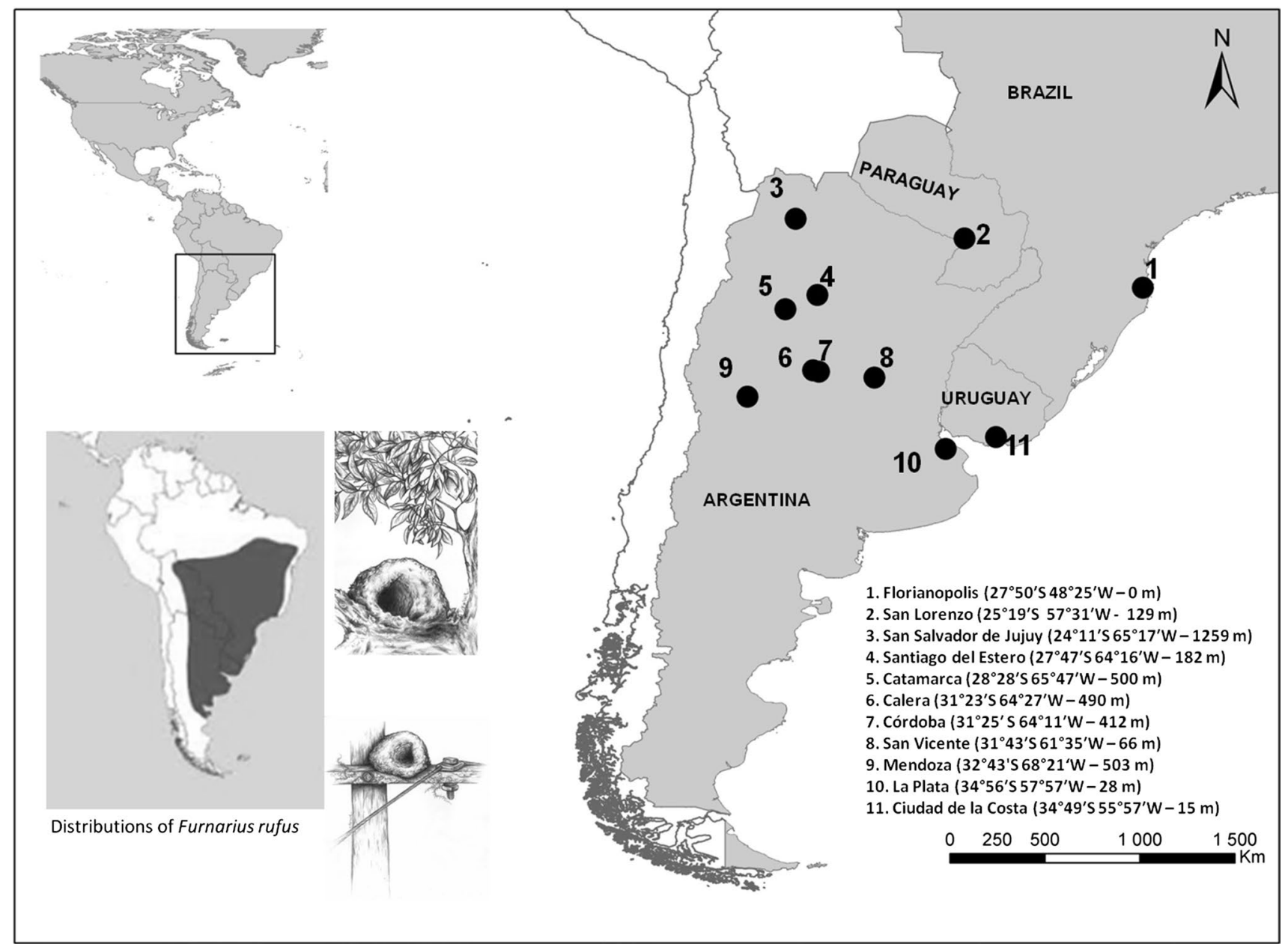

Fig. 1 Distribution of Rufous Hornero (bottom left) and drawings of Rufous Hornero nests (covered and uncovered; credit M. Morales). Right Map showing locations surveyed (numbered dark points), their names, geographical coordinates, and altitude (m a.s.l.)

would expect southern populations to orient their nest openings towards the north at higher latitudes (irrespective of vegetal cover), as they would benefit more from the warmer nest temperatures provided by a northerly exposure.

\section{Materials and methods}

\section{Data collection}

Data was collected at 11 sites in South America (Fig. 1) from September to March 2014-2016. Sites comprised rural, semi-urban or urban green areas with low building density. At each site, we systematically searched along randomly chosen transects for nests of Rufous Hornero on trees or lampposts during the species' breeding period. The complete data set consisted of 1291 nests (55\% of the nests were found on lampposts and $45 \%$ on trees). Nests close to each other placed on the same tree or lamppost were considered to be different. Although we did not confirm that all nests belonged to different nesting pairs, we believe this fact should not affect our conclusions through a pseudo-replication effect. The number of nests per site was distributed as follows: (1) Florianopolis, Brazil, $n=100$; (2) San Lorenzo, Paraguay, $n=69$; (3) San Salvador de Jujuy, Argentina, $n=153$; (4) Santiago del Estero, Argentina, $n=121$; (5) Catamarca, Argentina, $n=44$; (6) Calera, Argentina, $n=98$; (7) Córdoba, Argentina, $n=140$; (8) San Vicente, Santa Fé, Argentina, $n=151$; (9) Mendoza, Argentina, $n=106$; (10) La Plata, Argentina, $n=108$; (11) Ciudad de la Costa, Uruguay, $n=201$.

For each sampled nest we recorded nest entrance orientation using a compass, and vegetation cover. Vegetation cover was considered a categorical variable with two levels: those with $>75 \%$ of vegetation cover on top $(0.20-0.50 \mathrm{~m}$ above the nests) were considered protected nests, and nests fixed in places with scarce $(<25 \%)$ or no vegetation cover were considered unprotected. Although we followed the methods of 
Souza and Santos (2007), we selected two different groups of vegetation cover type in order to establish two well-defined extreme groups from a possible continuous range of vegetal coverage. All latitudinal points were corrected for magnetic declination from true north (Evans 2017).

\section{Statistical analysis}

We estimated and compared mean entrance orientation $( \pm \mathrm{SD})$ between different locations and levels of vegetation cover using circular statistics. Watson's $U^{2}$-test was used to determine if nest entrance was randomly distributed $(p>0.05)$ or directed $(p<0.05)$ (Zar 1999). To estimate differences in mean orientation values due to vegetation cover level and within a given location, we used a Watson-Williams $F$-test.

In order to find a northward compensation in nest entrance orientation with increasing latitudes, we divided the sites into two groups: northern sites and southern sites (the limit between the groups was set to $30^{\circ} \mathrm{S}$ ), and then compared mean nest entrance orientation of uncovered nests between groups. In addition, we analyzed the entrance orientation of covered nests. We finally compared mean nest entrance values of covered and uncovered nests of southern sites. All analyses were performed using Oriana software (Kovach Computing Services 2004). Data from locations 6 and 7 (Calera and Córdoba, in Argentina) were grouped for circular statistics.

We analyzed nest orientation patterns taking into account the variability between locations by linear mixed models (Zuur et al. 2009). Only, non-random nest entrance orientation was considered. Following Landler et al. (2014), angular deviation from north was used to linearize circular data regarding orientation, i.e., an orientation towards south would have the maximum value of 180 , and a northward orientation the minimum value of 0 . However, orientation towards east or west would both be 90 . Nest geographical position was averaged within site; therefore latitude was used as informative of longitude and altitude. In this way, the codependence of geographic location and vegetation cover were explored by type III error in ANOVA (Fox and Weisberg 2011). The analysis was performed in $\mathrm{R}$ version3.2.3 (R Core Team 2017) with lme4, car, dplyr and ggplot2 packages (Fox and Weisberg 2011; Wickham 2011, 2016; Bates et al. 2015). Normality and homogeneity of the residuals were analyzed by visual inspection of the error distribution pattern (Zuur et al. 2009).

\section{Results}

Results of Watson's $U^{2}$-test from the complete set of nests (without considering vegetation cover) revealed that nest entrance orientation is directed non-randomly at seven out of ten locations (70\%; Table 1). Localities showing random orientation included San Lorenzo (Paraguay), Santiago del Estero (Argentina), and Ciudad de La Costa (Uruguay).

With respect to the degree of vegetation cover and locality, the mean orientation of covered nests was towards the southwest (quadrant between $180^{\circ}$ and $270^{\circ}$; Fig. 2). On the other hand, uncovered nests at $60 \%$ of the sites were mostly oriented towards the north-west quadrant (between $270^{\circ}$ and $360^{\circ}$; Fig. 2; Table 1). The Watson-Williams $F$-test used for comparing differences in mean orientation values among vegetation cover type was significant at seven out of ten locations (Fig. 2). Only three locations (Catamarca, Argentina; Mendoza, Argentina; and Ciudad de la Costa, Uruguay) showed no variation in orientation between covered and uncovered nests (Fig. 2).

Covered nests at most localities $(70 \%)$ showed random entrance orientation with the exception of two localities, Catamarca and Mendoza. In these two cases only covered nest entrances were oriented (Table 1). On the other hand, half of the localities (50\%) showed directed orientation for uncovered nests, and $40 \%$ showed random orientation. In Catamarca, orientation of uncovered nests was not calculated due to the low number of uncovered nests registered. Uncovered nests were oriented toward the south-east in Florianopolis (Brazil) and toward the north-west in San Salvador de Jujuy, Córdoba, San Vicente, and La Plata (Argentina).

The comparison between mean nest orientation of uncovered nests from northern (nl) and southern latitudes (sl) showed significant differences $(F=118$; $p$-value $<0.0001)$. Uncovered nests at lower latitudes were oriented toward the south-east $\left(\mu_{\mathrm{nl}}=128.5, \mathrm{SD}=124^{\circ} ; U=0.21 ; p\right.$-value $\left.<0.05\right)$ and nests at higher latitudes were oriented in a northerly direction $\left(\mu_{\mathrm{sl}}=298, \mathrm{SD}=111.5^{\circ} ; U=0.73 ; p\right.$-value $\left.<0.005\right)$. Moreover, covered nests at lower latitudes showed random orientation patterns $\left(\mu_{\mathrm{nl}}=253^{\circ}, \mathrm{SD}=132^{\circ} ; U=0.17\right.$; $p$-value $>0.05$ ), while at higher latitudes they had a southwestern orientation $\left(\mu_{\mathrm{sl}}=251.5^{\circ}, \mathrm{SD}=118^{\circ}\right)$. Thus, covered and uncovered nests showed a significantly different orientation $(F=22.2 ; p$-value $<0.0001)$ at southern latitudes.

The pattern of linear nest entrance orientation was not affected by the joint effect of latitude and vegetation cover $\left(X^{2}=2.425 ; n=900 ; p\right.$-value $\left.=0.12\right)$ or the additive effect of latitude $\left(X^{2}=0.11 ; p\right.$-value $\left.=0.73\right)$ and vegetation cover $\left(X^{2}=1.57 ; p\right.$-value $\left.=0.21\right)$. Moreover, the linear orientation showed considerable variation between locations $\left(\sigma^{2}=30.48\right.$; Fig. 3$)$.

\section{Discussion}

Our results provide partial evidence for the solar radiation hypothesis regarding Rufous Hornero nest orientation (Burton 2007; Landler et al. 2014). When sites were grouped 
Table 1 Results from Watson's $U^{2}$-test, and $p$-values, considering the complete set of data and data separated according to vegetation cover $(>75$ or $<25 \%)$ at each site sampled $(1-11)$

\begin{tabular}{|c|c|c|c|c|c|c|c|c|c|c|}
\hline & \multicolumn{10}{|l|}{ Location } \\
\hline & 1 & 2 & 3 & 4 & 5 & 6 and 7 & 8 & 9 & 10 & 11 \\
\hline \multicolumn{11}{|l|}{ Total } \\
\hline$n$ & 100 & 69 & 153 & 121 & 44 & 238 & 151 & 106 & 108 & 201 \\
\hline$\mu$ & $139.752^{\circ}$ & $323.269^{\circ}$ & $210.266^{\circ}$ & $14.073^{\circ}$ & $240.226^{\circ}$ & $327.054^{\circ}$ & $282.725^{\circ}$ & $277.485^{\circ}$ & $293.39^{\circ}$ & $209.224^{\circ}$ \\
\hline $\mathrm{SD}$ & $100.813^{\circ}$ & $135.96^{\circ}$ & $161.25^{\circ}$ & $156.008^{\circ}$ & $90.329^{\circ}$ & $117.898^{\circ}$ & $106.725^{\circ}$ & $99.494^{\circ}$ & $96.315^{\circ}$ & $119.155^{\circ}$ \\
\hline$U^{2}$-test & 0.274 & 0.069 & 0.262 & 0.124 & 0.346 & 0.274 & 0.451 & 0.338 & 1.016 & 0.185 \\
\hline$p$-value & $<0.01$ & $>0.25$ & $<0.025$ & $>0.15$ & $<0.005$ & $<0.01$ & $<0.005$ & $<0.005$ & $<0.005$ & $>0.5$ \\
\hline \multicolumn{11}{|c|}{ Coverage $>75 \%$} \\
\hline$n$ & 6 & 40 & 121 & 54 & 38 & 105 & 61 & 46 & 60 & 40 \\
\hline$\mu$ & $208.757^{\circ}$ & $307.696^{\circ}$ & $180.283^{\circ}$ & $286.091^{\circ}$ & $223.278^{\circ}$ & $276.004^{\circ}$ & $244.839^{\circ}$ & $265.006^{\circ}$ & $114.461^{\circ}$ & $183.98^{\circ}$ \\
\hline $\mathrm{SD}$ & $74.955^{\circ}$ & $103.096^{\circ}$ & $151.184^{\circ}$ & $125.659^{\circ}$ & $102.444^{\circ}$ & $121.872^{\circ}$ & $103.98^{\circ}$ & $83.774^{\circ}$ & $143.974^{\circ}$ & $113.511^{\circ}$ \\
\hline$U^{2}$-test & $-{ }^{\mathrm{a}}$ & 0.114 & 0.118 & 0.071 & 0.211 & 0.119 & 0.145 & 0.338 & 0.127 & 0.094 \\
\hline$p$-value & $-^{\mathrm{a}}$ & $>0.15$ & $>0.15$ & $>0.25$ & $<0.05$ & $>0.15$ & $0>0.1$ & $<0.005$ & $>0.25$ & $>0.25$ \\
\hline \multicolumn{11}{|c|}{ Coverage $<25 \%$} \\
\hline$n$ & 94 & 29 & 32 & 67 & 6 & 133 & 90 & 60 & 48 & 161 \\
\hline$\mu$ & $133.081^{\circ}$ & $111.993^{\circ}$ & $309.693^{\circ}$ & $74.19^{\circ}$ & $262.952^{\circ}$ & $348.380^{\circ}$ & $305.295^{\circ}$ & $300.379^{\circ}$ & $293.484^{\circ}$ & $216.042^{\circ}$ \\
\hline SD & $100.004^{\circ}$ & $113.347^{\circ}$ & $136.341^{\circ}$ & $127.569^{\circ}$ & $14.991^{\circ}$ & $106.839^{\circ}$ & $101.389^{\circ}$ & $112.491^{\circ}$ & $57.827^{\circ}$ & $119.639^{\circ}$ \\
\hline$U^{2}$-test & 0.271 & 0.075 & 0.506 & 0.137 & $-^{\mathrm{a}}$ & 0.333 & 0.462 & 0.183 & 1.823 & 0.147 \\
\hline$p$-value & $<0.01$ & $>0.25$ & $<0.005$ & $>0.1$ & $-^{a}$ & $<0.005$ & $<0.005$ & $>0.05$ & $<0.005$ & $>0.1$ \\
\hline
\end{tabular}

$p$-values $<0.05$ in italics indicate non-random orientation

1 Florianopolis, Brazil, $n=100$; 2 San Lorenzo, Paraguay, $n=69 ; 3$ San Salvador de Jujuy, Argentina, $n=153$; 4 Santiago del Estero, Argentina, $n=121$; 5 Catamarca, Argentina, $n=44$; 6 Calera, Argentina, $n=98 ; 7$ Córdoba, Argentina, $n=140 ; 8$ San Vicente, Santa Fé, Argentina, $n=151 ; 9$ Mendoza, Argentina, $n=106 ; 10$ La Plata, Argentina, $n=108 ; 11$ Ciudad de la Costa, Uruguay, $n=201 ; n$ number of nests, $\mu$ mean orientation

${ }^{a}$ Values were not calculated because of low sample size $(n<10)$

Fig. 2 Mean entrance orientation values of nests of Rufous Hornero categorized by vegetation cover $(>75 \%$, black circles; $<25 \%$, gray circles) for each locality. The table shows the Watson-Williams $F$-test between covered versus uncovered nests of the same locality, and $p$-values. Asterisk indicates significant difference. For location names, see Fig. 1

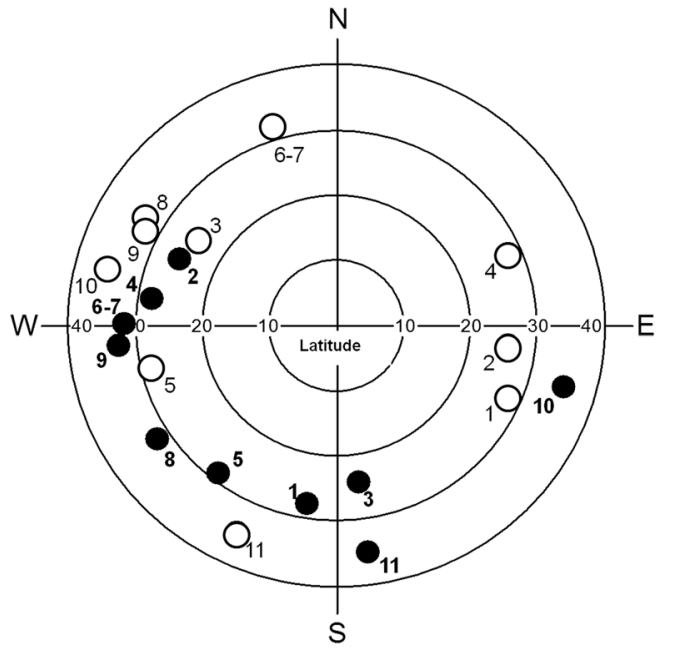

\begin{tabular}{ccl}
\hline \hline Sites & $\begin{array}{c}\text { Watson-Williams } \\
\text { Tests } \\
\text { (F) }\end{array}$ & \multicolumn{1}{c}{$\boldsymbol{p}$} \\
\hline 1 & 4.051 & $0.047^{*}$ \\
2 & 19.112 & $<0.001^{*}$ \\
3 & 16.861 & $<0.001^{*}$ \\
4 & 25.548 & $<0.001^{*}$ \\
5 & 1.707 & 0.198 \\
$6-7$ & 14.995 & $<0.001^{*}$ \\
8 & 9.243 & $0.003^{*}$ \\
9 & 2.414 & 0.123 \\
10 & 11.424 & $0.001^{*}$ \\
11 & 2.008 & 0.158 \\
\hline
\end{tabular}

according to latitude of entrances of uncovered (or poorly covered) nests, those at lower latitudes showed a non-random orientation toward southern directions as a way of compensation for higher solar radiation. Meanwhile, vegetal coverage might release bird orientation selection from the pressure imposed by solar radiation, as covered nests did not show any specific orientation at higher latitudes. Solar radiation is weaker at higher latitudes where Rufous Hornero nest orientation preference is expected to fit the mean yearly temperature hypothesis, which states that southern populations 
Fig. 3 Local source of variation in the nest entrance orientation of Rufous Hornero. Error bars Mean random effect \pm SD

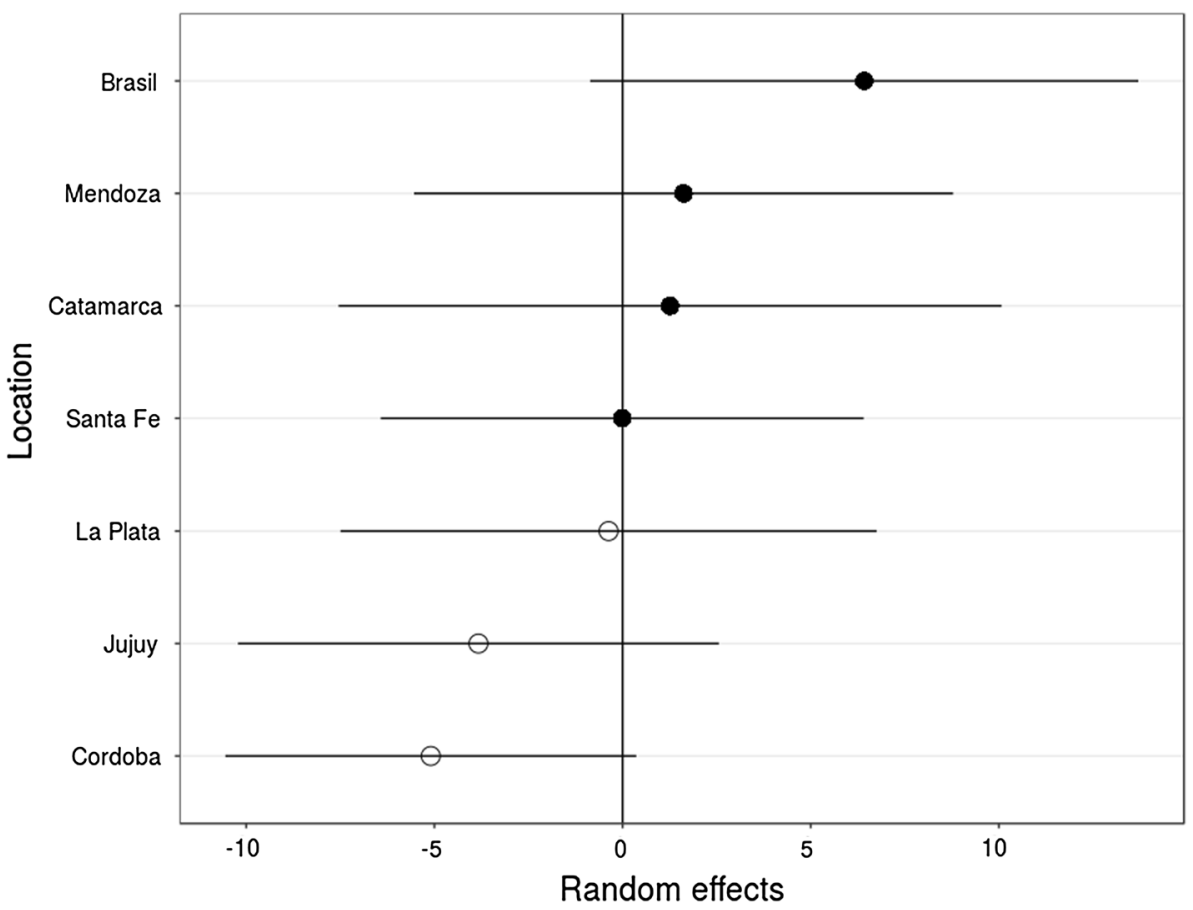

would benefit more from the warmer nest temperatures provided by a northerly exposure (Burton 2007). Therefore, the entrances of covered and uncovered nests may face north, yet the former faced the opposite way. This might be explained by other factors such as differences in altitude or prevailing winds, which remain unclear at a regional scale.

When analyzing data within sites, the results show a wide range of mean entrance orientation values between locations for both covered and uncovered nests, suggesting that nest orientation in the species may be explained by either random orientation (Souza and Santos 2007) or by different factors exerting some effect on nests orientation at a local scale such as microclimate, predation, and habitat structure (Conner 1975; Inouye 1976; Martin and Roper 1988; Bergin 1991; Norment 1993; Ardia et al. 2006; Burton 2006). Climatic differences across a species' breeding range can complicate the study of nest site selection (Hartman and Oring 2003). This study almost covers $30 \%$ of the species' geographic distribution; however, it represents the main occupancy area (eBird 2017). Thus, considering the geographic range and the diversity of places included in the analysis, different values in mean nest orientation between locations may reflect different local conditions.

Nests without vegetal protection showed directed entrance orientation at half of the places studied. For instance, uncovered nests in San Salvador de Jujuy, the highest sampled site (1260 $\mathrm{m}$ a.s.1.), were directed to the west. Due to the elevation, nests in San Salvador de Jujuy experience lower nighttime temperatures, so a western orientation would allow for higher temperatures due to the evening sun. Places at higher latitudes and lower altitude showed a tendency towards a northern direction. At the local level, our results disagree with Souza and Santos (2007) who found a random orientation pattern and an absence of vegetation cover effect. We found Brazilian nests to be directed, particularly uncovered nests (this could not be determined for nests with $>75 \%$ vegetation cover due to low sample size). Consequently, in southeastern Brazil, uncovered nests follow a rather nonrandom nest entrance orientation due to lack of vegetal protection.

Regarding vegetation cover, we found differences between mean entrance orientation values of covered and uncovered nests at seven locations. In Rufous Hornero vegetation cover could affect mean nest entrance orientation, suggesting that vegetation may offer extra protection under harsh climatic conditions related to intense insulating wind or prevailing storms, as reported for other bird species (Norment 1993; Hoekman et al. 2002). Future work is necessary to establish the effect exerted by vegetation cover on nest orientation with respect to Rufous Hornero nesting biology. This work should take into account a continuous vegetation cover scale, but also the structural configuration of the surrounding habitat of nests, as we found that orientation variance among locations differed.

The present results highlight the importance of analyzing vegetation cover as nest orientation patterns in birds (Hoekman et al. 2002; Souza and Santos 2007) might be related to it, causing random nest orientation values (Walsberg 1981; Norment 1993; With and Webb 1993). Other additive factors different from the ones tested here may have an effect 
on nest orientation (i.e., prevailing winds, risk of predation, habitat structure, nest height from the ground, and nesting site availability). Thus, the different local trends in the orientation of nests in the same region might be informative for these additive factors.

Our model results did not show an effect of vegetation cover or latitude on mean linear nest orientation values in Rufous Hornero. Latitude did not show the same effect as in cavity nesters like the Picidae from the Northern Hemisphere [i.e., at higher latitudes nests tend to face north (Landler et al. 2014)]. We possibly failed to prove the latitudinal effect as this hypothesis probably operates at extreme latitudes and, as mentioned above, the places considered in our study overlap most of the core distribution of the species. Moreover, the latitude effect may act at broader phylogenetic and geographic scales (Landler et al. 2014). Alternatively, the unique nest topology and materials used by Rufous Hornero (Fraga 1980; Shibuya et al. 2015) may provide enough insulation, counteracting the highest pairwise climatic-latitudinal cost.

To our knowledge, this is the first study in which the orientation of nest entrances has been analyzed in a species by considering several locations across its range of distribution. Future work including measures at more extreme latitudes of the species' distribution, or nests' inner temperatures related to nest orientation and top vegetation, would be interesting to test for their effects on reproductive success and nestling growth in this species (Ardia et al. 2006; DuRant et al. 2013).

Acknowledgments We gratefully acknowledge Carlos Toscano-Gadea and Macarena Gonzalez for helping us with the fieldwork. We also thank Marisel Morales who kindly made the drawings, and Erica Cuyckens, who provided us with the map. Sebastian Kennerknecht is warmly thanked for helping to improve the English of the manuscript. Finally, we want to thank two anonymous reviewers for their detailed comments, which have greatly improved the quality of the manuscript. A. A. Schaaf, C.G. García, E. Tallei, and A. I. E. Quaglia hold doctoral grants provided by CONICET.

\section{References}

Albano DJ (1992) Nesting mortality of Carolina Chickadees breeding in natural cavities. Condor 94:371-382

Ardia DR, Pérez JH, Clotfelter ED (2006) Nestbox orientation affects internal temperature and nest site selection by Tree Swallows. J Field Ornithol 77:339-344

Bates D, Maechler M, Bolker B, Walker S (2015) Fitting linear mixedeffects models using lme4. J Stat Softw 67:1-48

Bergin TM (1991) A comparison of goodness-of-fit tests for analysis of nest orientation in Western Kingbirds (Tyrannus verticalis). Condor 93:164-171

Brown M, Downs CT (2003) The role of shading behaviour in the thermoregulation of breeding Crowned Plovers (Vanellus coronatus). J Therm Biol 28:51-58
Burton NH (2006) Nest orientation and hatching success in the Tree Pipit Anthus trivialis. J Avian Biol 37:312-317

Burton NH (2007) Intraspecific latitudinal variation in nest orientation among ground-nesting passerines: a study using published data. Condor 109:441-446

Collias NE, Collias EC (1984) Nest building and bird behavior. Princeton University Press, Princeton

Conner RN (1975) Orientation of entrances to woodpecker nest cavities. Auk 92:371-374

Conway CJ, Martin TE (2000) Effects of ambient temperature on avian incubation behavior. Behav Ecol 11:178-188

Cook MI, Beissinger SR, Toranzos GA, Rodriguez RA, Arendt WJ (2003) Trans-shell infection by pathogenic micro-organisms reduces the shelf life of non-incubated bird's eggs: a constraint on the onset of incubation? Proc R Soc Lond B 270:2233-2240

DuRant SE, Hopkins WA, Hepp GR, Walters JR (2013) Ecological, evolutionary, and conservation implications of incubation temperature-dependent phenotypes in birds. Biol Rev 88:499-509

eBird (2017) eBird: an online database of bird distribution and abundance [web application]. eBird, Ithaca. http://www.ebird.org. Accessed 8 July 2017

Evans SW (2017) The effect of nest site orientation on the breeding success of Blue Swallows Hirundo atrocaerulea in South Africa. Afr J Ecol 56:91-100

Facemire CF, Facemire ME, Facemire MC (1990) Wind as a factor in the orientation of entrances of Cactus Wren nests. Condor 92:1073-1075

Fox J, Weisberg S (2011) Multivariate linear models in R. An R companion to applied regression. Sage, Thousand Oaks

Fraga RM (1980) The breeding of Rufous Horneros (Furnarius rufus). Condor 82:58-68

Hanssen SA, Hasselquist D, Folstad I, Erikstad KE (2005) Cost of reproduction in a long-lived bird: incubation effort reduces immune function and future reproduction. Proc R Soc Lond B 272:1039-1046

Hartman CA, Oring LW (2003) Orientation and microclimate of Horned Lark nests: the importance of shade. Condor 105:158-163

Hoekman ST, Ball IJ, Fondell TF (2002) Grassland birds orient nests relative to nearby vegetation. Wilson Bull 114:450-456

Hooge PN, Stanback MT, Koenig WD (1999) Nest-site selection in the Acorn Woodpecker. Auk 116:45-54

Inouye DW (1976) Nonrandom orientation of entrance holes to woodpecker nests in aspen trees. Condor 78:101-102

Inouye RS, Huntly NJ, Inouye DW (1981) Non-random orientation of Gila Woodpecker nest entrances in saguaro cacti. Condor 83:88-89

Kovach Computing Services (2004) Oriana software. Version 2.0

Landler L, Jusino MA, Skelton J, Walters JR (2014) Global trends in woodpecker cavity entrance orientation: latitudinal and continental effects suggest regional climate influence. Acta Ornithol 49:257-266

Lloyd JD, Martin TE (2004) Nest-site preference and maternal effects on offspring growth. Behav Ecol 15:816-823

Mainwaring MC, Hartley IR (2013) The energetic costs of nest building in birds. Avian Biol Res 6:12-17

Mainwaring MC, Hartley IR, Lambrechts MM, Deeming DC (2014) The design and function of birds' nests. Ecol Evol 4:3909-3928

Mainwaring MC, Barber I, Deeming DC, Pike DA, Roznik EA, Hartley IR (2016) Climate change and nesting behaviour in vertebrates: a review of the ecological threats and potential for adaptive responses. Biol Rev. https://doi.org/10.1111/brv.12317

Martin T, Roper J (1988) Nest predation and nest-site selection of a western population of the Hermit Thrush. Condor 90:51-57

Mezquida ET (2004) Nest site selection and nesting success of five species of passerines in a South American open Prosopis woodland. J Ornithol 145:16-22 
Nelson KJ, Martin K (1999) Thermal aspects of nest-site location for Vesper Sparrows and Horned Larks in British Columbia. Stud Avian Biol 19:137-143

Norment CJ (1993) Nest-site characteristics and nest predation in Harris' Sparrows and White-crowned Sparrows in the Northwest Territories, Canada. Auk 110:769-777

Peña MRDL (2005) Reproducción de las aves argentinas (con descripción de pichones). LOLA, Buenos Aires

Petersen KL, Best LB (1985) Nest-site selection by Sage Sparrows. Condor 87:217-221

R Core Team (2017) R: a language and environment for statistical computing. R Foundation for Statistical Computing, Vienna. https ://www.R-project.org/

Rauter CM, Reyer HU, Bollmann K (2002) Selection through predation, snowfall and microclimate on nest-site preferences in the Water Pipit Anthus spinoletta. Ibis. 144:433-444

Ridgely RS, Tudor G (1994) The birds of South America. The suboscine passerines, vol II. University of Texas Press, Austin

Shibuya FL, Braga TV, Roper JJ (2015) The Rufous Hornero (Furnarius rufus) nest as an incubation chamber. J Therm Biol 47:7-12

Souza FL, Santos CA (2007) Climate and nest opening orientation in Furnarius rufus (Furnariidae). Iheringia 97:293-295

Tarvin KA, Smith KG (1995) Microhabitat factors influencing predation and success of suburban Blue Jay Cyanocitta cristata nests. J Avian Biol 26:296-304

Viñuela J, Sunyer C (1992) Nest orientation and hatching success of Black Kites Milvus migrans in Spain. Ibis 134:340-345
Visser ME, Lessells CM (2001) The costs of egg production and incubation in Great Tits (Parus major). Proc R Soc Lond B 268:1271-1277

Walsberg GE (1981) Nest-site selection and the radiative environment of the Warbling Vireo. Condor 83:86-88

Webb DR (1987) Thermal tolerance of avian embryos: a review. Condor 89:874-898

Webb DR, King JR (1983) An analysis of the heat budgets of the eggs and nest of the White-crowned Sparrow, Zonotrichia leucophrys, in relation to parental attentiveness. Physiol Zool 56:493-505

Wickham A (2011) The split-apply-combine strategy for data analysis. J Stat Softw 40:1-29

Wiebe KL (2001) Microclimate of tree cavity nests: is it important for reproductive success in Northern Flickers? Auk 118:412-421

With KA, Webb DR (1993) Microclimate of ground nests: the relative importance of radiative cover and wind breaks for three grassland species. Condor 95:401-413

Zar JH (1999) Biostatistical analysis. Prentice Hall, Upper Saddle River

Zuur AF, Ieno EN, Walker NJ, Saveliev AA, Smith GM (2009) Mixed effects models and extensions in ecology with R. Springer, New York

Zwartjes PW, Nordell SE (1998) Patterns of cavity-entrance orientation by Gilded Flickers (Colaptes chrysoides) in cardon cactus. Auk 115:119-126

Zyskowski K, Prum RO (1999) Phylogenetic analysis of the nest architecture of Neotropical ovenbirds (Furnariidae). Auk 116:891-911

\section{Affiliations}

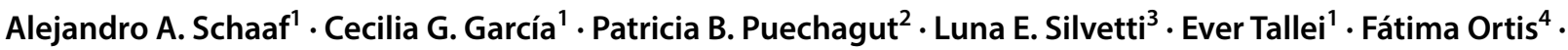 Agustín I. E. Quaglia ${ }^{5}$}

Cecilia G. García

cecigarciam@gmail.com

1 Instituto de Ecorregiones Andinas (INECOA), Universidad Nacional de Jujuy - Consejo Nacional de Investigaciones Científicas y Técnicas (CONICET), Avenida Bolivia 1239, 4600 San Salvador de Jujuy, Jujuy, Argentina

2 University Studies Abroad Consortium, Universidade Federal de Santa Catarina, Avenida Desembargador Vitor Lima, no. 222, Reitoria II, Térreo, Trindade, Florianópolis, SC CEP: 88040-400, Brazil
3 Facultad de Ciencias Exactas, Físicas y Naturales, Universidad Nacional de Córdoba, Avenida Vélez Sarsfield 299, X5000JJC Córdoba, Argentina

4 Paraguay Salvaje, Filadelfia 853, 9300 Fernheim, Paraguay

5 Laboratorio de Arbovirus-Instituto de Virología "Dr. J. M. Vanella"-Facultad de Ciencias Médicas, Universidad Nacional de Córdoba, Córdoba, Argentina 